\title{
Article \\ Synthesis of Zirconia Micro-Nanoflakes with Highly Exposed (001) Facets and Their Crystal Growth
}

\author{
Haibo Yan ${ }^{1,2,3 \oplus}$, Jian $\mathrm{Di}^{1,3}$, Jiahao $\mathrm{Li}^{4}$, Zhuoyu Liu ${ }^{1}$, Junfeng Liu ${ }^{4}$ and Xing Ding ${ }^{1,2,3, * \mathbb{C}}$ \\ 1 State Key Laboratory of Isotope Geochemistry, Guangzhou Institute of Geochemistry, \\ Guangzhou 510640, China; yanhaibo@gig.ac.cn (H.Y.); dijian@gig.ac.cn (J.D.); lzhy1598@163.com (Z.L.) \\ 2 CAS Center for Excellence in Deep Earth Science, Guangzhou 510640, China \\ 3 College of Earth and Planetary Sciences, University of Chinese Academy of Sciences, Beijing 100049, China \\ 4 School of Earth Science and Resources, Chang'an University, Xi'an 710054, China; \\ 2019127041@chd.edu.cn (J.L.); junfengliu@chd.edu.cn (J.L.) \\ * Correspondence: xding@gig.ac.cn
}

Citation: Yan, H.; Di, J.; Li, J.; Liu, Z.; Liu, J.; Ding, X. Synthesis of Zirconia Micro-Nanoflakes with Highly Exposed (001) Facets and Their Crystal Growth. Crystals 2021, 11, 871. https://doi.org/10.3390/cryst11080871

Academic Editors: Maged F. Bekheet and Ulla Simon

Received: 9 June 2021

Accepted: 23 July 2021

Published: 27 July 2021

Publisher's Note: MDPI stays neutral with regard to jurisdictional claims in published maps and institutional affiliations.

Copyright: (c) 2021 by the authors. Licensee MDPI, Basel, Switzerland. This article is an open access article distributed under the terms and conditions of the Creative Commons Attribution (CC BY) license (https:// creativecommons.org/licenses/by/ $4.0 /)$.

\begin{abstract}
This study reports a novel preparation method of zirconia micro-nanoflakes with high (001) facets that is generated through a hydrolysis reaction of the fluozirconic acid $\left(\mathrm{H}_{2} \mathrm{ZrF}_{6}\right)$. Zirconia micro-nanoflakes synthesized at varied conditions were analyzed by the SEM, EDS, $\mu$-XRD, and Raman spectroscopy to characterize the morphology and probe into the crystal growth mechanism. The synthesized zirconia crystals in the form of elliptical micro-nanoflakes or irregular nanoflakes generally display the highly exposed (001) facets with a thickness of 1-100 nm and a length of 0.1-2.0 $\mu \mathrm{m}$. As the temperature and initial solution concentration increased, the particle sizes of the synthesized zirconia micro-nanoflakes became more uniform and the thicknesses of the (001) facets became larger, suggesting that the synthesized zirconia crystals grow along the (001) facets and mostly along the $c$-axis direction. This is confirmed by the data from the $\mu$-XRD patterns. The results also demonstrate that an oriented attachment-based growth occurring in a fluorine-rich solution environment was involved in the aggregation and coarsening of zirconia micro-nanoflakes. Meanwhile, synthesized zirconia micro-nanoflakes also evolved from a mixture of monoclinic and tetragonal systems to a pure monoclinic system (i.e., baddeleyite) with the temperature increasing, suggesting a key role of temperature regarding zirconia's growth.
\end{abstract}

Keywords: baddeleyite; zirconia; micro-nanoflake; fluozirconic acid; high (001) facets; hydrolysis

\section{Introduction}

Zirconia $\left(\mathrm{ZrO}_{2}\right)$, as a kind of significant structural and functional material, has excellent physical and chemical properties including a high melting point (as high as $2700{ }^{\circ} \mathrm{C}$ ), high boiling point, high strength, low thermal conductivity, a large thermal expansion coefficient, and good ionic conductivity, and is wear-resistant, high-temperature-resistant, corrosion-resistant, and oxidation-resistant [1,2]. As of 1980s, apart from its use as a traditional refractory material and ceramic glaze, zirconia has received increasingly more attention for application in the fields of energy, environment, and material [1,3-6]. The performances of micro-nano zirconia in the aspects of optics, mechanics, thermodynamics, and electromagnetism are different from those of conventional materials due to its tiny size. As a result, micro-nano zirconia displays extensive application uses in the industrial synthesis, catalysts and catalyst carriers, unique ceramics, thermal barrier coatings, refractory materials, cutting tools, sensors, solid batteries, decoration, adsorption, and reinforcing and toughening fields [5,7-14]. Therefore, micro-nano zirconia has been considered one of the most valuable functional materials in the 21st century.

Preparation of micro-nano zirconia is generally divided into physical and chemical approaches. The physical approach includes a reactive plasma processing method, freezedrying method, explosive compaction-coating method, and spray pyrolysis method, among 
others $[13,15,16]$. In contrast, the chemical approach mainly involves an emulsion method, direct precipitation method, lamellar liquid crystal template method, sol-gel method, and hydrothermal method [4,14,17-19]. Multiple reagents such as raw materials, precipitators, stabilizing agents, and solvents are adopted in the foregoing synthesis processes. Currently, the most widely adopted synthetic raw materials mainly include zirconium oxychloride octahydrate $\left(\mathrm{ZrOCl}_{2} \cdot 8 \mathrm{H}_{2} \mathrm{O}\right)$, aqueous zirconium nitrate $\left(\mathrm{ZrO}\left(\mathrm{NO}_{3}\right)_{2} \cdot \mathrm{xH}_{2} \mathrm{O}\right)$, zirconium nitrate $\left(\mathrm{Zr}\left(\mathrm{NO}_{3}\right)_{4} \cdot 5 \mathrm{H}_{2} \mathrm{O}\right)$, and zirconium (IV) chloride $\left(\mathrm{ZrCl}_{4}\right)$, as well as inorganic or organic reagents as the precipitators (such as sodium hydroxide, ammonia water, docusate sodium, and urea), inorganic reagents as the stabilizing agents (such as silver nitrate, calcium chloride, yttrium chloride, and yttrium oxide), and organic reagents as the solvents or polymerization inhibitors (such as polyethylene glycol, absolute ethyl alcohol, sodium lauryl sulfate, n-butanol, cyclohexane, isopropanol, n-ethanol, and Span-80) [10,20-23].

Previous studies demonstrated that the physicochemical properties of zirconia not only depend on the chemical components and phase structure of zirconia but also on the morphology, size, and surface area of zirconia [24]. Therefore, in recent years, many methods have been used to prepare zirconia materials with different morphologies and sizes so as to promote the performances or exploit new properties of zirconia. Currently, zirconia crystals with various morphologies or structures have already been successfully synthesized by using different synthetic raw materials and preparation methods such as nanopowder, nanorod, nanofiber, micro-nanofiber, micro-nano whisker, nanotube, microsphere, films, and composite materials, among other [3-9,11,14,16,17,19,25-31].

In this paper, we first adopted a pyrohydrolysis method to synthesize a kind of micro-nanoflaky zirconia with high (001) facets. Throughout the whole process, only two reagents (fluozirconic acid and ethanol) were used as the starting materials. The zirconia micro-nanoflakes are uniform and have high exposed (001) facets, and could have great application prospects in the fields of adsorption, catalysis, sensors, and ceramic materials.

\section{Materials and Methods}

\subsection{Reagents and Instruments}

The starting reagent, fluozirconic acid $\left(\mathrm{H}_{2} \mathrm{ZrF}_{6}, 45\right.$ wt. $\%$ in $\mathrm{H}_{2} \mathrm{O}$, Macklin, Shanghai, China) with a density of $1.512 \mathrm{~g} / \mathrm{cm}^{3}$, is one of the most stable chemicals among $\mathrm{Zr}-\mathrm{F}$ complexes at room temperature and ambient pressure, and gradually hydrolyzes at high temperatures and high pressures. The starting reagent was diluted with deionized water to produce the initial solutions with concentrations of 0.01 and $0.02 \mathrm{~mol} \cdot \mathrm{L}^{-1}$. Note that the fluozirconic acid is a highly corrosive and toxic chemical, and all operations related to fluozirconic acid should be conducted in a fume hood and operators must protect themselves by wearing protective masks, clothing, and gloves when working with it.

All synthesis experiments were performed in the cold-seal pressure vessels with a $27 \mathrm{~mm}$ outer diameter, $6 \mathrm{~mm}$ inner diameter, and $250 \mathrm{~mm}$ length using water as a pressure medium. It is connected with a high-precision high-pressure gauge ( $\pm 5 \mathrm{MPa})$ measured with a NiCr-Ni thermocouple $\left( \pm 5^{\circ} \mathrm{C}\right)$ [32-34]. A constant temperature drying oven $\left( \pm 1^{\circ} \mathrm{C}\right.$, DGG-9070B, Jiangdong) was used for the post-processing of synthetic products [35,36]. All synthesis processes were conducted at the hydrothermal laboratory of the Guangzhou Institute of Geochemistry, China.

A SU8010 field-emission scanning electron microscope (SEM) (HITACHI, Tokyo, Japan) equipped with an EDAX Apollo x-SDD energy dispersive spectrometer (Core Lab, Tulsa, OK, USA) with a working voltage of $15 \mathrm{kV}$ and magnification of 600-80,000 was used for the morphological analysis of the synthesized crystals at the State Key Laboratory of Organic Geochemistry of the Guangzhou Institute of Geochemistry, China. A Dmax RAPID V micro-area X-ray Diffraction ( $\mu$-XRD) (Rigaku, Tokyo, Japan) with a working voltage of $40 \mathrm{kV}$, working current of $30 \mathrm{~mA}$, exposure time of $100 \mathrm{~s}$, and collimator of $0.1 \mathrm{~mm}$ was used for the structure analysis of the synthesized crystals at the CAS Key Laboratory of Mineralogy and Metallogeny of the Guangzhou Institute of Geochemistry, China. The qualitative analysis of the synthesized crystals was conducted by a WITec 
alpha 300R high-resolution confocal Raman spectrometer (Germany) that was equipped with three lasers $(488,532$, and $633 \mathrm{~nm})$, three gratings (300, 600, and 1800 grooves/mm), and four Zeiss objectives $(5 \times, 20 \times, 50 \times$, and $100 \times)$ at the hydrothermal laboratory of Guangzhou Institute of Geochemistry, China [37].

\subsection{Synthesis Procedure}

First, well-prepared diluted initial solutions of $\mathrm{H}_{2} \mathrm{ZrF}_{6}$ with concentrations of 0.01 and $0.02 \mathrm{~mol} \cdot \mathrm{L}^{-1}$ were injected into a gold capsule with a diameter of $4 \mathrm{~mm}$ and length of $30 \mathrm{~mm}$ to account for $30-80 \%$ of the volume of the capsule while the capsule was sealed at both ends with a tungsten insert gas welding system (PUK U3, Germany). Before and after all synthesis experiments, the capsule was checked for leaks by placing it into the drying oven at $110{ }^{\circ} \mathrm{C}$ for at least $2 \mathrm{~h}$. Only those capsules with negligible mass differences were used in the synthesis experiments. The gold capsule was then placed into the end of the pressure vessel and pressurized and heated to the designed pressure and temperature. After the run was completed, the vessel was quickly quenched in an ice-water mixture. Finally, the gold capsule was opened and washed 2-3 times with deionized water and ethanol and dried in a constant temperature drying oven. A zirconia layer of micro-nanoflakes with high (001) facets that was formed on the inner surface of the gold was also subsequently analyzed.

\section{Results and Discussion}

During the synthesis experiment, the dissolved $\mathrm{H}_{2} \mathrm{ZrF}_{6}$ could become unstable with increasing temperature and pressure, and could gradually hydrolyze due to the hydrolysis of $\mathrm{Zr}$ (IV) cation [38,39]. The cumulative hydrolysis reaction and formation of zirconia precipitates can be described as:

$$
\mathrm{H}_{2} \mathrm{ZrF}_{6}+2 \mathrm{H}_{2} \mathrm{O}=\mathrm{ZrO}_{2} \downarrow+6 \mathrm{HF}
$$

The above reaction generally reached an equilibrium of hydrolysis within a few hours at $200{ }^{\circ} \mathrm{C}$ and $100 \mathrm{MPa}$, producing zirconia crystals and hydrogen fluoride, and demonstrated a strong dependence on temperature and initial solution concentration $[33,36]$. To avoid the effect of runtime for synthesis products, all synthesis experiments were conducted with a longer duration (12-14 h). The synthesized products are identified as zirconia crystals by the EDS (Figure 1), Raman spectrum (Figure 2), and $\mu$-XRD (Figure 3). The morphology analysis results from the SEM images demonstrated that synthesized zirconia crystals were in the form of elliptical micro-nanoflakes or irregular micro-nanoflakes, 1-100 $\mathrm{nm}$ thick and 0.1-2 $\mu \mathrm{m}$ long, with highly exposed (001) facets (Figures 4 and 5). The histogram of the long-axis sizes for these synthesized zirconia crystals almost displayed a normal distribution (Figure 6). The long-axis sizes of the synthesized zirconia at $200{ }^{\circ} \mathrm{C}$, $250{ }^{\circ} \mathrm{C}, 300{ }^{\circ} \mathrm{C}$ varied between $0.1-2.0 \mu \mathrm{m}, 0.1-1.0 \mu \mathrm{m}$, and $0.1-2.0 \mu \mathrm{m}$, and had peaks at $0.8-1.0 \mu \mathrm{m}, 0.5-0.8 \mu \mathrm{m}$, and $0.6-1.0 \mu \mathrm{m}$, respectively. By contrast, the sizes of zirconia crystals synthesized at $400{ }^{\circ} \mathrm{C}$ and $500{ }^{\circ} \mathrm{C}$ were more uniform, ranging between $0.4-1.0 \mu \mathrm{m}$ and $0.4-2.0 \mu \mathrm{m}$, and higher peaks ranged between $0.7-0.9 \mu \mathrm{m}$ and 1.2-1.5 $\mu \mathrm{m}$ than those of 200-300 ${ }^{\circ} \mathrm{C}$ (Figure 5). Other synthesis procedure and results are shown in Table 1.

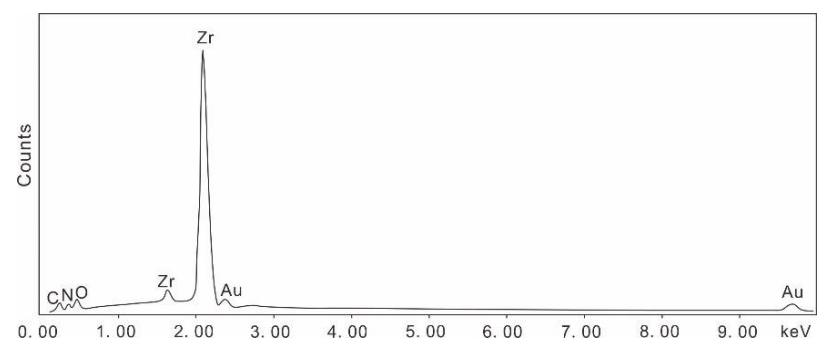

Figure 1. Representative EDS analysis of zirconia micro-nanoflakes adhered to the inner surface of gold capsule. Note that $\mathrm{N}$ could derive from the starting initial solutions and Au is derived from the gold capsule. 
Table 1. Preparation on zirconia micro-nanoflakes with high (001) facets under varied conditions.

\begin{tabular}{ccccccc}
\hline No. & $\begin{array}{c}\text { Initial Concentration } \\
(\mathbf{m o l} / \mathbf{L})\end{array}$ & $\begin{array}{c}\text { Temperature } \\
\left({ }^{\circ} \mathbf{C}\right)\end{array}$ & $\begin{array}{c}\text { Pressure } \\
(\mathbf{M P a})\end{array}$ & $\begin{array}{c}\text { Time } \\
(\mathbf{h})\end{array}$ & $\begin{array}{c}\text { Thickness } \\
(\mathbf{n m})\end{array}$ & $\begin{array}{c}\text { Length } \\
(\boldsymbol{\mu m})\end{array}$ \\
\hline 1 & 0.02 & 200 & 100 & 12 & $1-50$ & $0.1-2.0$ \\
\hline 2 & 0.01 & 250 & 80 & 14 & $10-50$ & $0.1-1.0$ \\
\hline 3 & 0.02 & 250 & 100 & 12 & $10-50$ & $0.1-1.0$ \\
\hline 4 & 0.02 & 300 & 120 & 12 & $20-80$ & $0.1-2.0$ \\
\hline 5 & 0.02 & 400 & 100 & 12 & $50-100$ & $0.5-1.0$ \\
\hline 6 & 0.01 & 400 & 80 & 12 & $20-80$ & $0.5-1.0$ \\
\hline 7 & 0.01 & 500 & 80 & 12 & $50-80$ & $0.5-1.0$ \\
\hline 8 & 0.02 & 500 & 80 & 12 & $50-100$ & $0.5-2.0$ \\
\hline
\end{tabular}

\subsection{Temperature Dependence on the Crystal Form and the Morphology of the Synthesized Zirconia}

The synthesis temperature has an important influence on the crystal form of synthesized zirconia based on the result of the Raman analysis. As shown in Figure 2, the results of the Raman spectrum show that 14 Raman characteristic peaks of synthesized zirconia at $200{ }^{\circ} \mathrm{C}$ and $250{ }^{\circ} \mathrm{C}$ are similar to that of the standard baddeleyite (monoclinic system). In addition, 6 Raman characteristic peaks of synthesized zirconia appear at $144 \mathrm{~cm}^{-1}$, $258 \mathrm{~cm}^{-1}, 318 \mathrm{~cm}^{-1}, 462 \mathrm{~cm}^{-1}, 612 \mathrm{~cm}^{-1}$, and $640 \mathrm{~cm}^{-1}$, which is consistent to that of the Raman spectrum for the tetragonal system, indicating a mixture of monoclinic and tetragonal systems at $200{ }^{\circ} \mathrm{C}$ and $250{ }^{\circ} \mathrm{C}$. The Raman spectrum of synthesized zirconia demonstrated that it is a monoclinic system mixed with a few amounts of the tetragonal system at $300{ }^{\circ} \mathrm{C}$ but is a pure monoclinic system at $400{ }^{\circ} \mathrm{C}$ and $500{ }^{\circ} \mathrm{C}$ (Figure 2). The consistent results were also demonstrated by the $\mu$-XRD spectrum (Figure 3 ). Therefore, the synthesized zirconia is a pure monoclinic system at elevated temperatures $\left(\geq 400^{\circ} \mathrm{C}\right)$ but is a mixture of monoclinic and tetragonal systems at a relatively lower temperature $\left(\leq 300^{\circ} \mathrm{C}\right)$. This suggests that elevated temperatures can promote the growth of a monoclinic system and reduce the formation of a tetragonal system in the experimental temperature range.

In addition to the crystal form of synthesized products, temperature also has an important effect on the hydrolytic reaction's degree and morphology of hydrolytic products $[32,34-36,40]$. In this study, as the temperature increases, the morphology of synthesized zirconia also varied. For example, at similar synthesis conditions such as an initial solution concentration of $0.02 \mathrm{~mol} \cdot \mathrm{L}^{-1}$, pressure of $100 \mathrm{MPa}$, and runtime of $12 \mathrm{~h}$, the synthesized zirconia is in the form of an elliptical micro-nanoflake with a thickness of 1-50 nm and length of $0.1-2.0 \mu \mathrm{m}$ at $200{ }^{\circ} \mathrm{C}$ (Figure $4 \mathrm{a}$ ), and in contrast, at $250{ }^{\circ} \mathrm{C}$, it is in the form of an elliptical micro-nanoflake or irregular micro-nanoflake with a thickness of 10-50 nm and length of $0.1-1.0 \mu \mathrm{m}$ (Figure $4 \mathrm{~b}$ ); additionally, it changes to a form with a thickness of 50-100 $\mathrm{nm}$ and length of $0.5-1.0 \mu \mathrm{m}$ at $400{ }^{\circ} \mathrm{C}$ (Figure $4 \mathrm{~d}$ ). The results demonstrate that the synthesized zirconia becomes more uniform in particle size and thicker in the (001) facets from 10-50 nm to 50-100 $\mathrm{nm}$ and longer in the diameter from 0.1-1.0 $\mu \mathrm{m}$ to $0.5-1.0 \mu \mathrm{m}$ as the temperature increases from $200{ }^{\circ} \mathrm{C}$ to $400{ }^{\circ} \mathrm{C}$ (Figure 6). Compared to the morphology of zirconia at other synthesis conditions, zirconia synthesized at $500{ }^{\circ} \mathrm{C}$ has a larger crystal size (i.e., $50-100 \mathrm{~nm}$ thick and $0.5-2.0 \mu \mathrm{m}$ long) than those at $200-400{ }^{\circ} \mathrm{C}$ (Figures $4 \mathrm{e}, \mathrm{f}$ and 5). This also suggests that elevated temperatures can promote the growth of zirconia by increasing its size and the thickness of the (001) facet considering the possible effect of pressure. Similarly, compared to zirconia's morphology synthesized at $250-500{ }^{\circ} \mathrm{C}$ and a lower initial solution concentration of $0.01 \mathrm{~mol} \cdot \mathrm{L}^{-1}$ (Figure 5), the effect of temperature for the growth of zirconia with the (001) facets can be observed even in the case of inconsistent pressure and time. The influence of temperature on the morphology of synthesized zirconia could be explained by the process of hydrolytic reaction. As the temperature increases, the degree of hydrolytic reaction will increase, resulting in Equation (1) moving to the right and forming more precipitates and HF [36]. Hence, a large amount of $\mathrm{ZrO}_{2}$ 
precipitated from the solution can facilitate zirconia's growth, resulting in an increase of zirconia in size.

\subsection{Effect of Initial Solutions' Concentration on the Morphology of the Synthesized Zirconia}

Apart from the temperature, the initial solution concentration of $\mathrm{H}_{2} \mathrm{ZrF}_{6}$ also has a positive effect on the morphology of the synthesized zirconia. As shown in Figures $4 \mathrm{e}, \mathrm{f}$ and $5 c, d$, at the same synthesis conditions including the temperature of $500{ }^{\circ} \mathrm{C}$, pressure of $80 \mathrm{MPa}$, and runtime of $12 \mathrm{~h}$, the synthesized zirconia crystals grow from small irregular micro-nanoflakes (50-80 $\mathrm{nm}$ thick and $0.5-1.0 \mu \mathrm{m}$ long) at $0.01 \mathrm{~mol} \cdot \mathrm{L}^{-1}$ of the initial solution to larger elliptical micro-nanoflakes or irregular micro-nanoflakes (50-100 nm thick and $0.5-2.0 \mu \mathrm{m}$ long) at $0.02 \mathrm{~mol} \cdot \mathrm{L}^{-1}$ of the initial solution. The synthesized zirconia at a high initial solution concentration is also larger in size than that of a low initial solution concentration (Figure $4 b, d$ and Figure 5a,b). These results suggest a promotive effect of high initial solution concentration on the growth of the synthesized zirconia. This could also be explained by the degree of the hydrolytic reaction of $\mathrm{H}_{2} \mathrm{ZrF}_{6}$. With the concentration of the initial $\mathrm{H}_{2} \mathrm{ZrF}_{6}$ solution increasing, Equation (1) will move to the right and form a large amount of precipitates and HF, resulting in the growth and aggregation of the synthesized zirconia micro-nanoflake with high (001) facets [34,36].

\subsection{Growth Mechanism of the Synthesized Zirconia}

Crystal nucleation and growth is usually involved in the conventional atom-by-atom growth model, non-classical particle aggregation, and amorphous transformation [41,42]. In the present study, as the temperature increased, $\mathrm{H}_{2} \mathrm{ZrF}_{6}$ in the solutions hydrolyzed to produce zirconia precipitates that subsequently experienced nucleation, aggregation, and coarsening to generate zirconia micro-nanoflakes in addition to the phase transformation. A basic observation would state that as the temperature and initial solution concentration increases, the particle size of the synthesized zirconia micro-nanoflakes becomes more uniform and the thicknesses of the (001) facets becomes larger, suggesting that the synthesized zirconia crystals grow mostly along the (001) facets and c-axis. This is also confirmed by the data derived from the $\mu$-XRD patterns. As shown in Figure 3, the peak intensity of (001), (111), (-111), and (200) facets increases as the temperature increase from $200{ }^{\circ} \mathrm{C}$ to $500{ }^{\circ} \mathrm{C}$. Given that the (111), (-111), (022), and (200) facets are perpendicular or nearly perpendicular to the (001) facets, they grow mainly along the c-axis and can induce the thickening of the (001) facets significantly. Remarkably, the ratios of $\mathrm{I}_{(111)} / \mathrm{I}_{(001)}, \mathrm{I}_{(-111)} / \mathrm{I}_{(001)}, \mathrm{I}_{(200)} / \mathrm{I}_{(001)}$ all rise from $200{ }^{\circ} \mathrm{C}$ to $500{ }^{\circ} \mathrm{C}$ (Figure 7) which could indicate a fast growth rate of the flank facets along the $c$-axis direction at high temperatures, resulting in the faster growth of those facets over the (001) facets.

Note that the synthesized zirconia crystals could grow the (001) facets mostly prior to the hydrolysis equilibrium of $\mathrm{H}_{2} \mathrm{ZrF}_{6}$. As the hydrolysis of $\mathrm{H}_{2} \mathrm{ZrF}_{6}$ can produce $\mathrm{HF}$, surface fluorine of the zirconia micro-nanoflake could play a key role in stabilizing the (001) facets considering fluorine's role in the growth of the anatase (001) facets [43]. During the growth of zirconia, fluorine anions generated by ionization of HF from the hydrolytic reaction adhere to the (001) facets of zirconia to reduce the surface energy and promote the growth of the (001) facets. Meanwhile, $\mathrm{HF}$ or $\mathrm{H}^{+}$in the solutions could inhibit the growth of other facets of zirconia micro-nanoflakes compared to the ideal monoclinic zirconia crystal (Figure 8A). During the hydrolysis, the amount of precipitation driven by the hydrolysis of $\mathrm{H}_{2} \mathrm{ZrF}_{6}$ could be maximized which induces the (001) facets to grow at a very high rate; however, when the hydrolysis reaches equilibrium, the amount of precipitation would be reduced and causes a slower growth rate [44]. In the present study, all zirconia micro-nanoflakes were synthesized within a long duration that is sufficient for the $\mathrm{H}_{2} \mathrm{ZrF}_{6}$ to reach equilibrium, finally causing a major growth along the c-axis direction by the oriented attachment mechanism (Figure 8B). The oriented attachment-based growth results in the changes of zirconia micro-nanoflakes in terms of size, thickness, and superficial area to ensure that the (001) facets are well developed as other crystal facets gradually 
develop (Figure 8B). The highly exposed (001) facets for the new zirconia micro-nanoflakes likely have great application potentials on catalysis, adsorption, sensors, and ceramic materials $[5,26]$.

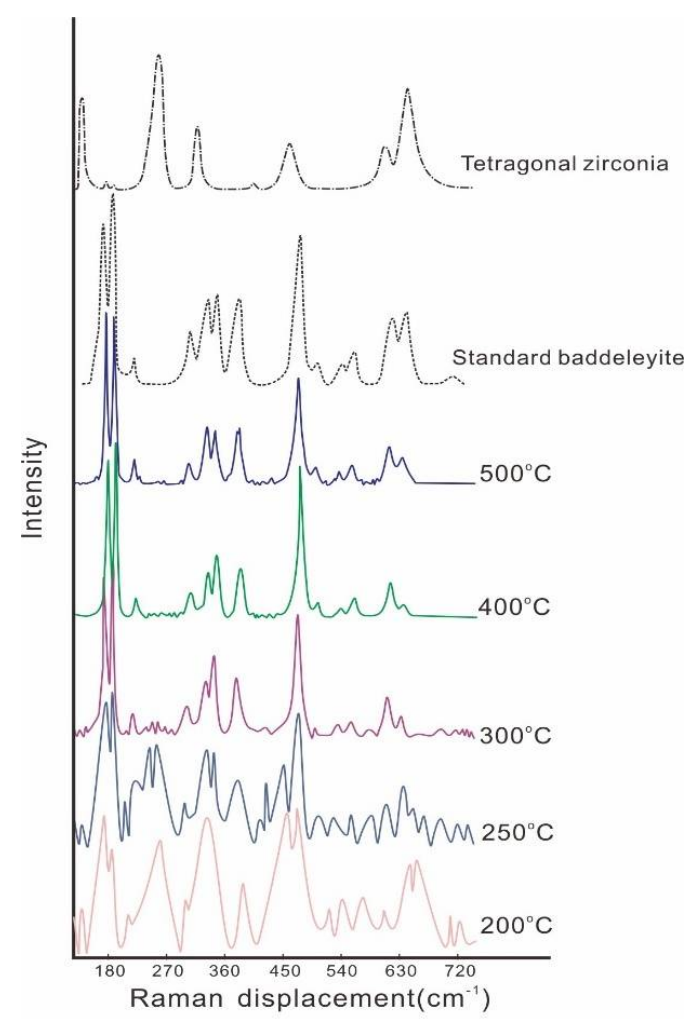

Figure 2. Raman spectra of zirconia micro-nanoflakes synthesized in the present study and standard monoclinic (e.g., baddeleyite) and tetragonal zirconia $\left(\mathrm{ZrO}_{2}\right)$ crystals. The standard Raman spectrum of baddeleyite is derived from an online Raman database (https:/ / rruff.info/baddeleyite/display= default/R060016 (accessed on 8 May 2021), while the Raman spectrum of tetragonal zirconia $\left(\mathrm{ZrO}_{2}\right)$ is from Reference [45].

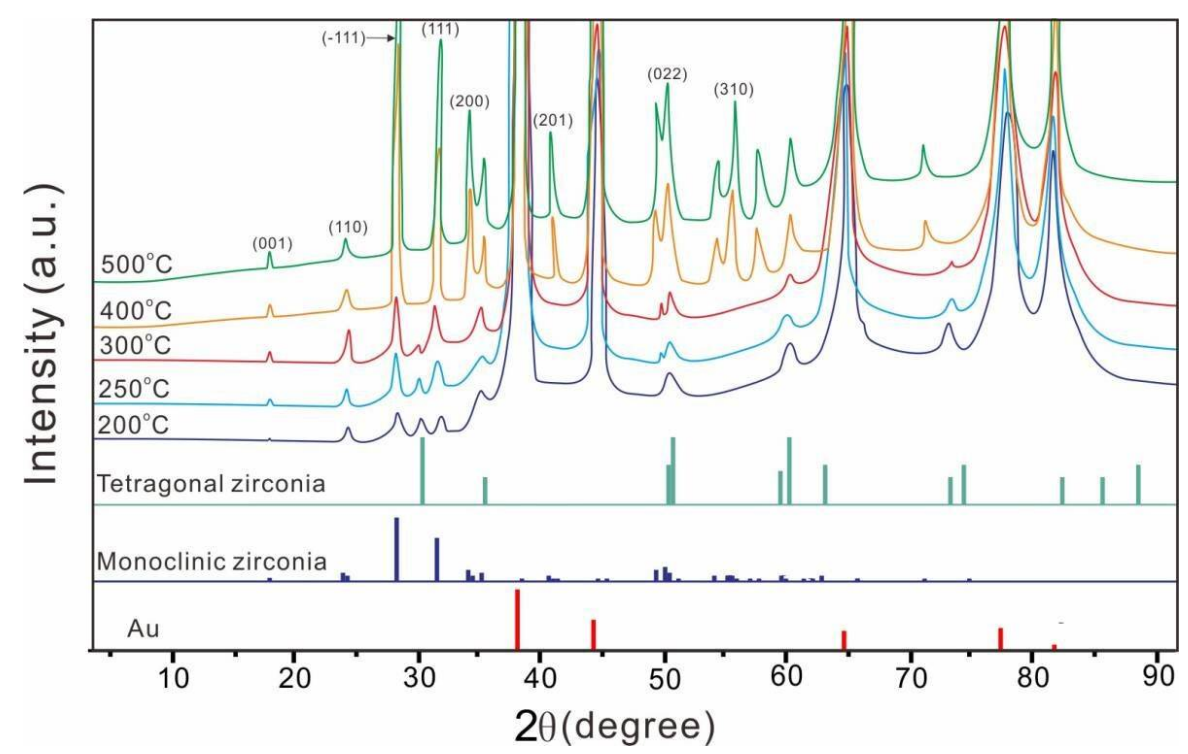

Figure 3. Representative XRD analysis of zirconia micro-nanoflakes synthesized at $200-500{ }^{\circ} \mathrm{C}$. The XRD spectra of $\mathrm{Au}$, monoclinic zirconia $\left(\mathrm{ZrO}_{2}\right)$, and tetragonal zirconia $\left(\mathrm{ZrO}_{2}\right)$ are from the database (No.00-004-0784, 00-037-1484, and 00-002-0733). 


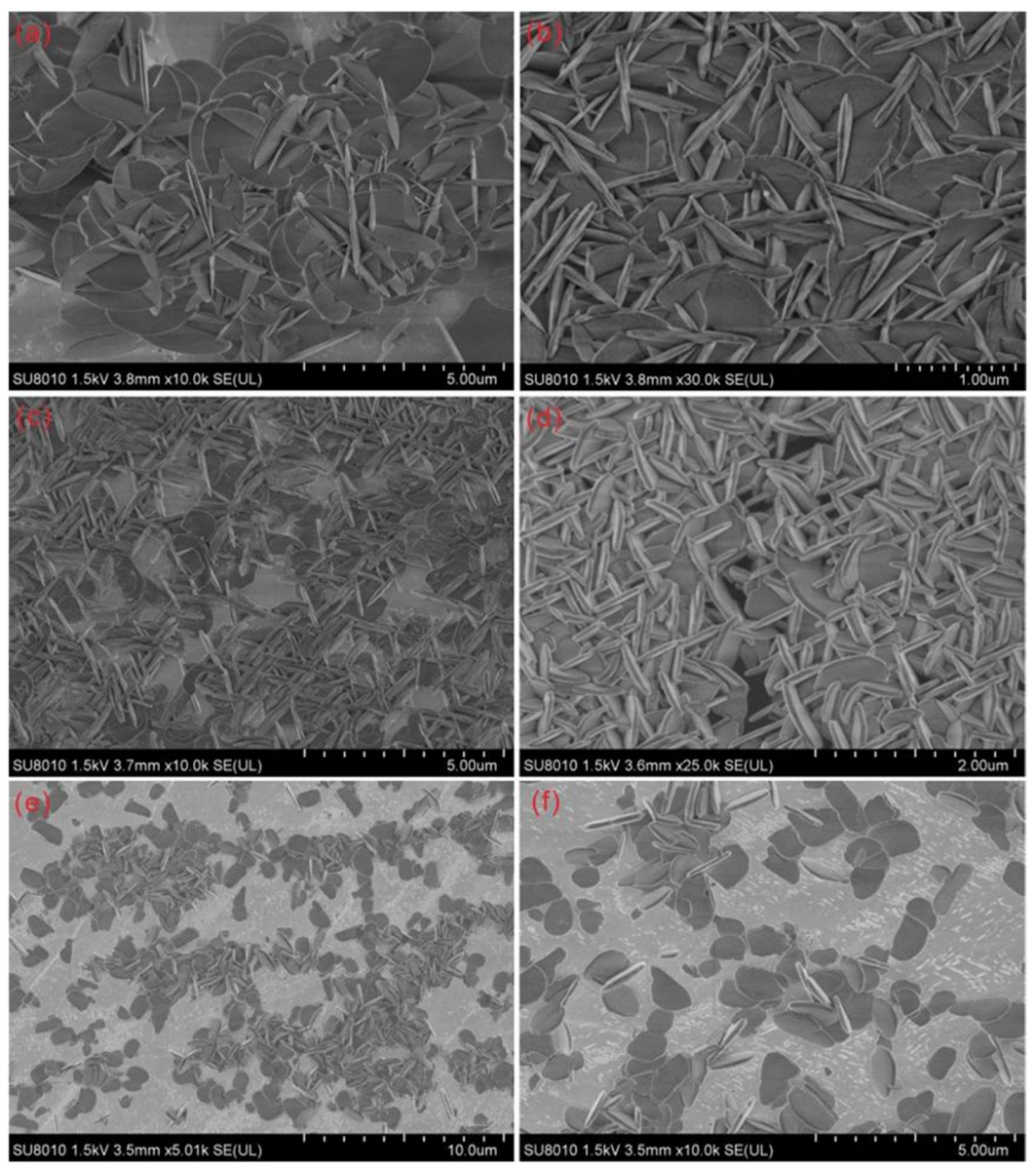

Figure 4. Representative SEM micrographs of zirconia micro-nanoflakes synthesized by $0.02 \mathrm{~mol} / \mathrm{L}$ of the initial solution concentration: (a) No. 1 at $200{ }^{\circ} \mathrm{C}, 100 \mathrm{MPa}$, and $12 \mathrm{~h}$; (b) No. 3 at $250{ }^{\circ} \mathrm{C}$, $100 \mathrm{MPa}$, and $12 \mathrm{~h}$; (c) No. 4 at $300^{\circ} \mathrm{C}, 120 \mathrm{MPa}$, and $12 \mathrm{~h}$; (d) No. 5 at $400{ }^{\circ} \mathrm{C}, 100 \mathrm{MPa}$, and $12 \mathrm{~h}$; and $(\mathbf{e}, \mathbf{f})$ No. 8 at $500{ }^{\circ} \mathrm{C}, 80 \mathrm{MPa}$, and $12 \mathrm{~h}$.

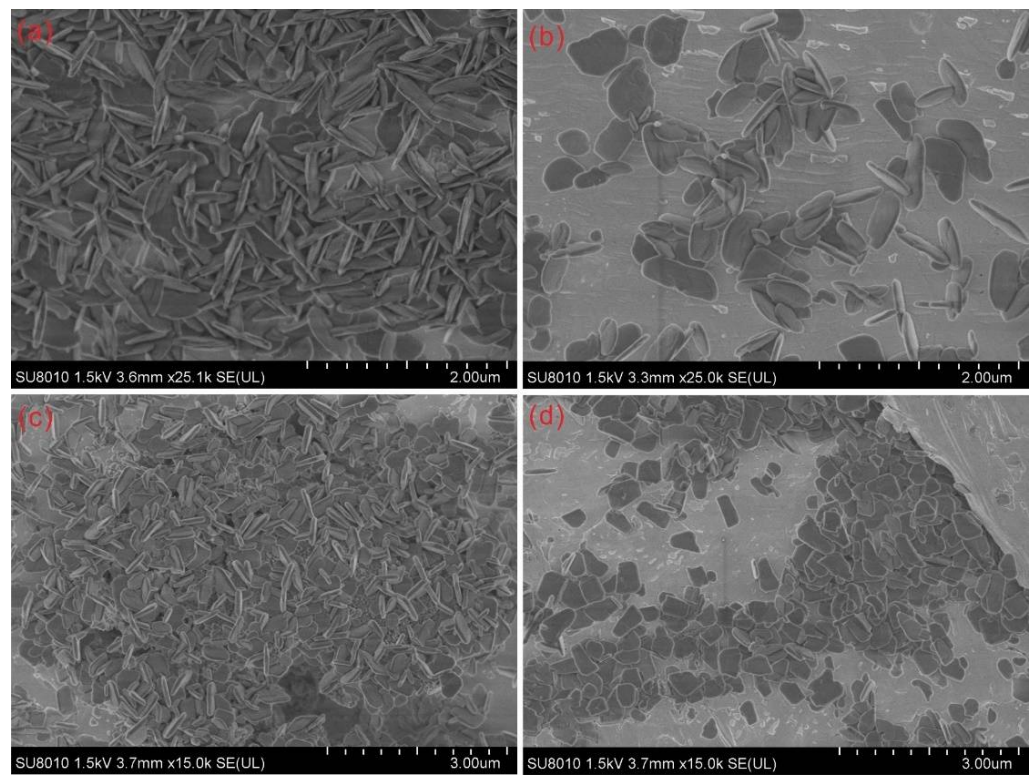

Figure 5. Representative SEM micrographs of zirconia micro-nanoflakes synthesized by $0.01 \mathrm{~mol} / \mathrm{L}$ of the initial solution concentration: (a) No. 2 at $250{ }^{\circ} \mathrm{C}, 80 \mathrm{MPa}$, and $14 \mathrm{~h}$; (b) No. 6 at $400{ }^{\circ} \mathrm{C}, 80 \mathrm{MPa}$, and $12 \mathrm{~h}$; and (c,d) No. 7 at $500{ }^{\circ} \mathrm{C}, 80 \mathrm{MPa}$, and $12 \mathrm{~h}$. 


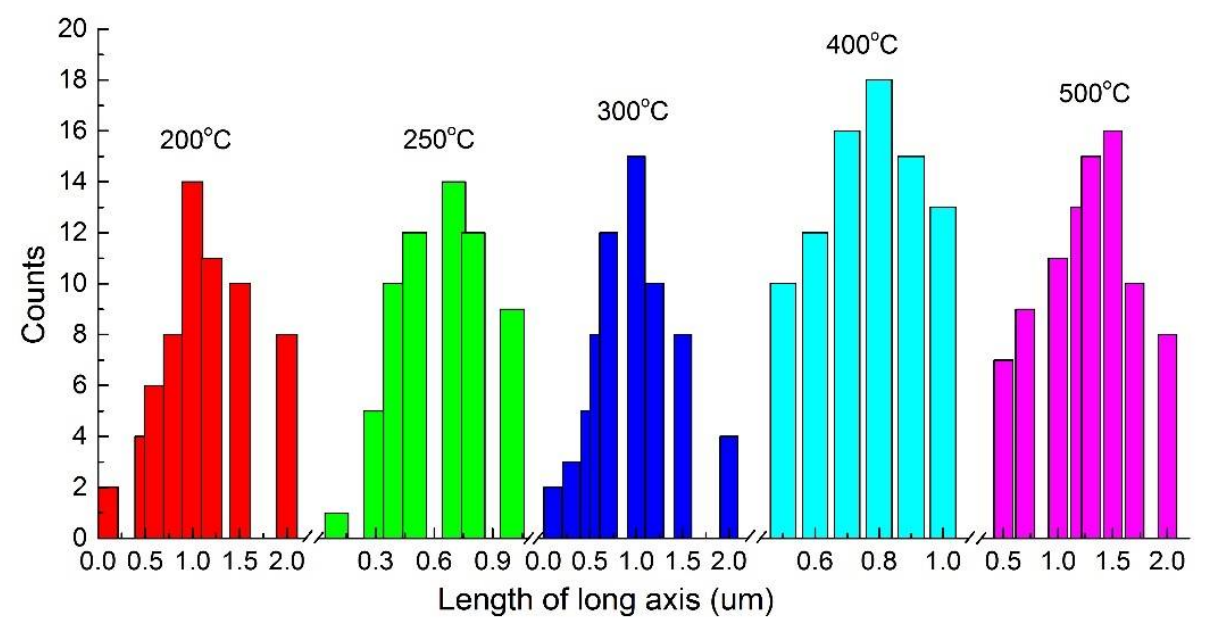

Figure 6. Statistical histograms of long-axis sizes for zirconia micro-nanoflakes $\left(\mathrm{ZrO}_{2}\right)$ synthesized at 250-500 ${ }^{\circ} \mathrm{C}$.

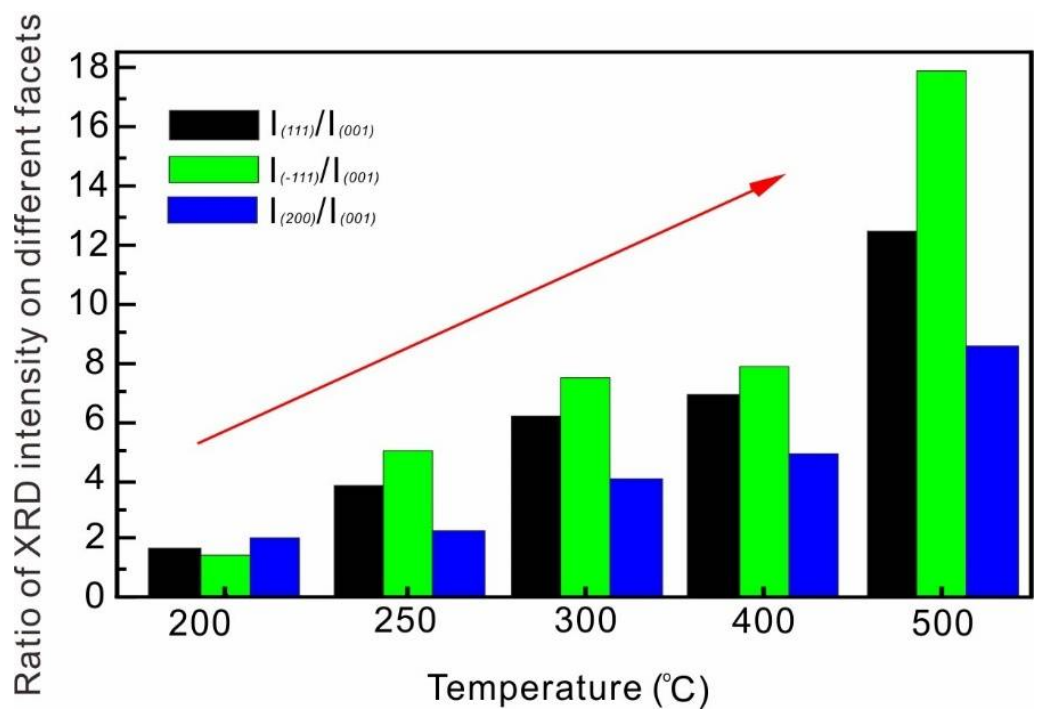

Figure 7. A histogram illustrating the ratios on the $\mu$-XRD intensity of the (111), (-111), and (200) facets compared to the (001) facets. As the temperature increases, all the ratios rise, suggesting that the growth of flank facets causes the thickening of zirconia micro-nanoflakes.

A

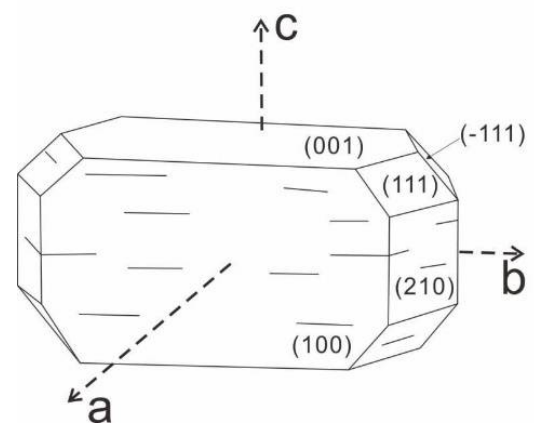

B

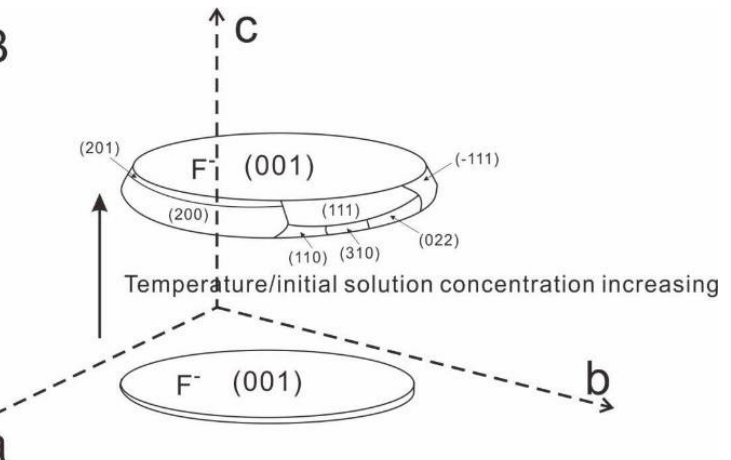

Figure 8. A schematic diagram of zirconia crystals with high (001) facets, demonstrating (A) the crystallographic structure of an ideal monoclinic zirconia (e.g., baddeleyite) and (B) a growth model for zirconia micro-nanoflakes. 


\section{Conclusions}

In this paper, we synthesized zirconia micro-nanoflakes with high (001) facets at $200-500{ }^{\circ} \mathrm{C}$ and $80-120 \mathrm{MPa}$ by a pyrohydrolysis procedure of $\mathrm{H}_{2} \mathrm{ZrF}_{6}$. Zirconia crystals synthesized are 1-100 $\mathrm{nm}$ thick and $0.1-2.0 \mu \mathrm{m}$ long elliptical or irregular micro-nanoflakes that are highly exposed in the (001) facets. The zirconia micro-nanoflakes belong to a mixture of monoclinic and tetragonal systems at the temperatures of $\leq 300{ }^{\circ} \mathrm{C}$ but belong to a pure monoclinic system at the temperatures of $\geq 400{ }^{\circ} \mathrm{C}$. As the temperature and initial $\mathrm{H}_{2} \mathrm{ZrF}_{6}$ concentration increase, the synthesized zirconia micro-nanoflakes become more uniform, mostly derived from the growth along the (001) facets. The increasing $\mu-$ XRD intensity of the (111), (-111), and (200) facets and the increasing ratios of $\mathrm{I}_{(111)} / \mathrm{I}_{(001)}$, $\mathrm{I}_{(-111)} / \mathrm{I}_{(001)}, \mathrm{I}_{(200)} / \mathrm{I}_{(001)}$ from $200{ }^{\circ} \mathrm{C}$ to $500{ }^{\circ} \mathrm{C}$ indicate an oriented attachment-based major growth along the c-axis that results in the thickening of the (001) facets with increasing temperatures. This suggests that the oriented attachment-based growth occurring in the fluorine-rich solution environment was involved in the aggregation and coarsening of zirconia micro-nanoflakes.

Author Contributions: Conceptualization, X.D.; methodology, X.D., Z.L. and J.L. (Junfeng Liu); formal analysis, J.D., H.Y. and J.L. (Jiahao Li); investigation, H.Y., J.D., Z.L. and J.L. (Jiahao Li); writing - original draft preparation, X.D. and H.Y.; writing—review and editing, J.L. (Junfeng Liu); visualization, X.D. and H.Y.; project administration, X.D. and J.L. (Junfeng Liu); funding acquisition, X.D. All authors have read and agreed to the published version of the manuscript.

Funding: This study was funded by the National Natural Science Foundation of China, grant number (41773054).

Institutional Review Board Statement: Not applicable.

Informed Consent Statement: Not applicable.

Data Availability Statement: Data sharing is not applicable to this article.

Acknowledgments: We thank the two anonymous reviewers and also Xavier Zang, Ulla Simon, and Maged F. Bekheet for their constructive comments and suggestions. This is also a contribution from GIGCAS, number IS-3053.

Conflicts of Interest: The authors declare no conflict of interest.

\section{References}

1. Zhou, P. Preparation and Characterization of Zirconia Ceramic Hollow Shells; Harbin Institute of Technology: Harbin, China, 2009.

2. Chang, J.P.; Lin, Y.S.; Chu, K. Rapid thermal chemical vapor deposition of zirconium oxide for metal-oxide-semiconductor field effect transistor application. J. Vac. Sci. Technol. B Microelectron. Nanometer Struct. Proc. Meas. Phenom. 2001, 19, $1782-1787$. [CrossRef]

3. Yu, H.; Wang, Z.Y.; Zhu, G.D.; Dai, Y.; Wang, Y.B.; Liu, J.Y. Electrospun Zirconia Nanofibre-modified Glassy Carbon Electrode for Determination of Methyl Parathion. Chin. J. Anal. Chem. 2018, 46, 1982-1989. (In Chinese with English)

4. He, W.Y.; Liu, J.R.; Cao, Z.Z.; Li, C.H.; Gao, Y.F. Preparation and characterization of monodisperse zirconia spherical nanometer powder via lamellar liquid crystal template method. Chin. J. Chem. Eng. 2015, 23, 1721-1727. [CrossRef]

5. Wijayanti, R.B.; Rosmayanti, I.; Wahyudi, K.; Maryani, E.; Hernawan, H.; Septawendar, R. Preparation of magnesia partially stabilized zirconia nanomaterials from zirconium hydroxide and magnesium carbonate precursors using PEG as a template. Crystals 2021, 11, 635. [CrossRef]

6. Gao, Q.W.; Jiang, W.H.; Liu, J.M.; Feng, G.; Chen, T.; Miao, L.F. Preparation of Zirconia Nanorods by Molten Salt Method. Chin. J. Inorg. Chem. 2017, 33, 1555-1560. (In Chinese with English Abstract)

7. Kang, J.; Ji, W.L.; Bu, J.L.; Chen, Y.; Wei, H.Y.; Lv, D.F.; Cui, Y.; Chen, Y.J.; Wei, Y.N.; Gong, L.P.; et al. Study on process of electrospinning preparation of zirconia hollow microspheres. Refract. Mater. 2018, 53, 170-175. (In Chinese with English Abstract)

8. Gao, Q.W.; Liu, J.M.; Jiang, W.H.; Feng, G.; Chen, T.; Miao, L.F. Effect of Solvothermal Temperature on the Preparation of Zirconia Whiskers. J. Ceram. 2018, 39, 154-158. (In Chinese with English Abstract)

9. Kwon, J.H.; Choi, J.H.; Bae, J.H.; Park, J. Hysteresis reduction for organic thin film transistors with multiple stacked functional zirconia polymeric films. Crystals 2019, 9, 634. [CrossRef]

10. Zhu, J.F.; Xiao, D.; Li, C.Y.; Huang, J.F.; Yong, X.; Cao, L.Y.; Fei, J. Microwave hydrothermal synthesis and crystallization mechanism of tetragonal phase zirconia nanocrystalline. J. Shaanxi Univ. Sci. Technol. (Nat. Sci. Ed.) 2015, 33, 60-68. 
11. Wu, J.; Lu, Y.F.; Liu, Y.; Yu, Z.Y.; Xin, B.F. Fabrication and Characterization of ZrO2 Nanofibers with Controllable Crystalline Phase by a Halid-free Approach. Chem. J. Chin. Univ. Chin. Ed. 2015, 36, 1403-1408. (In Chinese with English Abstract)

12. Pan, L.; Xu, H.B.; Sun, Y.Y.; Zhao, J.P.; Li, Y. Preparation of three-dimensional photonic crystals of zirconia by electrodeposition in a colloidal crystals template. Crystals 2016, 6, 76. [CrossRef]

13. Jayakumar, S.; Ananthapadmanabhan, P.V.; Perumal, K.; Thiyagarajan, T.K.; Mishra, S.C.; Su, L.T.; Tok, A.; Guo, J. Characterization of nano-crystalline $\mathrm{ZrO}_{2}$ synthesized via reactive plasma processing. Mater. Sci. Eng. B 2011, 176, 894-899. [CrossRef]

14. Noh, H.J.; Seo, D.S.; Kim, H.; Lee, J.K. Synthesis and crystallization of anisotropic shaped $\mathrm{ZrO}_{2}$ nanocrystalline powders by hydrothermal process. Mater. Lett. 2003, 57, 2425-2431. [CrossRef]

15. Binner, J.; Vaidhyanathan, B. Processing of bulk nanostructured ceramics. J. Eur. Ceram. Soc. 2008, 28, 1329-1339. [CrossRef]

16. Gaudon, M.; Djurado, E.; Menzler, N.H. Morphology and sintering behaviour of yttria stabilised zirconium (8-YSZ) powders synthesised by spray pyrolysis. Ceram. Int. 2004, 30, 2295-2303. [CrossRef]

17. Soo, M.T.; Prastqmo, N.; Matsuda, A.; Kawamura, G.; Muto, H.; Noor, A.; Lockman, Z.; Cheong, K.Y. Elaboration and characterization of sol-gel derived $\mathrm{ZrO}_{2}$ thin films treated with hot water. Appl. Surf. Sci. 2012, 258, 5250-5258. [CrossRef]

18. Garg, N.; Mittal, V.K.; Bera, S.; Dasgupta, A.; Sankaralingam, V. Preparation and characterization of tetragonal dominant nanocrystalline $\mathrm{ZrO}_{2}$ obtained via direct precipitation. Ceram. Int. 2012, 38, 2507-2512. [CrossRef]

19. Chang, Y.; Li, X.B. Preparation of ZrO2 spherical nanometer powders. J. Cent. South. Univ. (Sci. Technol.) 2007, 38, 46-50. (In Chinese with English Abstract)

20. Silva Junior, E.; Antonio, S.G.; Longo, E. Synthesis and structural evolution of partially and fully stabilized $\mathrm{ZrO}_{2}$ from a versatile method aided by microwave power. Ceram. Int. 2018, 44, 3517-3522. [CrossRef]

21. Wang, X.X.; Lin, J.W.; Zhan, Y.H.; Zhang, Z.B.; Chu, M. Adsorption of Phosphate from Aqueous Solution on Hydrous Zirconium Oxides Precipitated at Different pH Values. Enviorn. Sci. 2017, 38, 1936-1946. [CrossRef]

22. Ji, Y.; Han, L.Z.; Zheng, W.Q.; Wang, Q.; Yang, H.Z. Influence of pH values on different zirconia systems. Chin. J. Tissue Eng. Res. 2017, 21, 4131-4136.

23. Wang, H.Y.; Guo, Z.S.; Xing, G.E.; Song, X.Q. Study on Preparing Nano-sized $\mathrm{ZrO}_{2}$ by Different Techniques. J. Synth. Cryst. 2006, 35, 753-756.

24. Wang, J.J. Research progress of photocatalytic performance of nanometer zirconia. Light Ind. Stand. Qual. 2017, 2, 68-69. (In Chinese)

25. Li, W.; Liu, F.H.; Wu, D.W. Preparation of Flexible Yttria-stabilized Zirconia Nanofibers. Guangzhou Chem. Ind. 2018, 46, 45-51. (In Chinese with English Abstract)

26. Xu, G.F.; Song, H.Z.; Yang, D.L. The Hdrothermal Preparation of Stable Zirconia Nano Powder. Surf. Technol. 2017, 46, 95-100. [CrossRef]

27. Du, P.; Zhang, J.F.; Zhao, J.L.; Wang, X.X.; Zhang, L.B. Study on decolourization and degradation of methyl rrange by stirultrasonic ZrO2 nanotubes. J. Synth. Cryst. 2015, 44, 2518-2523. (In Chinese with English Abstract)

28. Wang, X.X.; Zhao, J.L.; Guo, L.M.; Yu, X.; Tang, C.C. Fabrication of Zirconia Nanotube Arrays on Curved Surface of Zirconium Wire. Rare Met. Mat. Eng. 2012, 41, 35-37. (In Chinese with English Abstract)

29. Li, J. Study on performance of nanometer zirconia-cerium oxide composites. Sci. Technol. Inf. 2014, 3, 51-79. (In Chinese with English Abstract)

30. Guo, J.H.; Li, X.H.; Li, Z.W.; Du, Z.L.; Zhang, Z.J. Synthesis of sheet-like silica/zirconia nanocomposites by sol-gel process. Chem. Res. 2011, 22, 49-54.

31. Yang, S.F. Study on liquid phase reaction self-assembly preparation and performance of $\mathrm{ZrO}_{2}$ films. Tianjin Chem. Ind. 2015, 29, 31-33.

32. Yan, H.B.; Sun, W.D.; Liu, J.F.; Tu, X.L.; Ding, X. Thermodynamic properties of ruthenium (IV) chloride complex and the transport of ruthenium in magmatic-hydrothermal fluids. Ore Geol. Rev. 2021, 131, 104043. [CrossRef]

33. He, J.J.; Ding, X.; Wang, Y.R.; Sun, W.D. The effects of precipitation-aging-re-dissolution and pressure on hydrolysis of fluorinerich titanium complexes in hydrothermal fluids and its geological implications. Acta Pet. Sin. 2015, 31, 1870-1878. (In Chinese with English Abstract)

34. He, J.J.; Ding, X.; Wang, Y.R.; Sun, W.D. The effect of temperature and concentration on hydrolysis of fluorine-rich titanium complexes in hydrothermal fluids: Constraints on titanium mobility in deep geological processes. Acta Pet. Sin. 2015, 31, 802-810. (In Chinese with English Abstract)

35. Di, J.; Yan, H.B.; Liu, Z.Y.; Ding, X. Synthesis and Characterization of Anatase $\mathrm{TiO}_{2}$ Microspheres Self-Assembled by Ultrathin Nanosheets. Materials 2021, 14, 2870. [CrossRef]

36. Yan, H.B.; He, J.J.; Liu, X.W.; Wang, H.B.; Liu, J.F.; Ding, X. Thermodynamic Investigation of the Hydrolysis Behavior of Fluorozirconate Complexes at 423.15-773.15 K and 100 MPa. J. Solut. Chem. 2020, 49, 836-848. [CrossRef]

37. Zhang, L.; Wang, Q.; Ding, X.; Li, W.C. Diverse serpentinization and associated abiotic methanogenesis within multiple types of olivine-hosted fluid inclusions in orogenic peridotite from northern Tibet-Science Direct. Geochim. Cosmochim. Acta 2021, 296, 1-17. [CrossRef]

38. Baes, J.C.F.; Mesmer, R.E. The thermodynamics of cation hydrolysis. Am. J. Sci. 1980, 281, 935-962. [CrossRef]

39. Ding, X.; Harlov, D.E.; Chen, B.; Sun, W.D. Fluids, metals, and mineral/ore deposits. Geofluids 2018, 1452409. [CrossRef] 
40. Wang, Y.R.; Chou, I.M. Characteristics of hydrolysis of the complex Na2SnF6 in hydrothermal solutions-An experimental study. Chin. J. Geochem. 1987, 6, 372-382. [CrossRef]

41. Lee, G.S.; Lee, Y.J.; Yoon, K.B. Layer-by layer assembly of zeolite crystals on glass with polyelectrolytes as ionic linkers. J. Am. Chem. Soc. 2001, 123, 9769-9779. [CrossRef]

42. De Yoreo, J.J.; Gilbert, P.U.P.A.; Sommerdijk, N.A.J.M.; Penn, R.L.; Whitelam, S.; Joester, D.; Zhang, H.Z.; Rimer, J.D.; Navrotsky, A.; Banfield, J.F.; et al. Crystallization by particle attachment in synthetic, biogenic, and geologic environments. Science 2015, 349, aaa6760. [CrossRef]

43. Yang, H.G.; Sun, C.H.; Qiao, S.Z.; Zou, J.; Liu, G.; Smith, S.C.; Cheng, H.M.; Lu, G.Q. Anatase TiO 2 single crystal with a large percentage of reactive facets. Nature 2008, 453, 638-642. [CrossRef] [PubMed]

44. Ding, X.; He, J.J.; Liu, Z.Y. Experimental studies on crystal growth of anatase under hydrothermal conditions. Earth Sci. 2018, 43, 1763-1772.

45. Bouvier, P.; Lucazeau, G. Raman spectra and vibrational analysis of nanometric tetragonal zirconia under high pressure. J. Phys. Chem. Solids 2000, 61, 569-578. [CrossRef] 